\section{Lattice Constant of Grey Tin}

THE erystal structure of $\alpha$-tin (grey tin) is given by Bijl and Kolkineiger ${ }^{1}$ as a diamond-type structure, having $a=6 \cdot 46 \mathrm{~A}$,, and the X-ray density as $5 \cdot 81 \mathrm{gm} . \mathrm{cm}^{-3}$.

We have been supplied with a sample of grey tin prepared by Mr. J. T. Kendall of the City and Guilds College, London, and have measured its lattice spacing at room temperature. Nickel-filtered copper radiation was used. Assuming $\lambda$ for copper $K \alpha_{1}=$ $1.54050 \mathrm{~A} .{ }^{2}$, the lattice spacing in absolute angstrom units is $6.4912 \pm 0.0005 \mathrm{~A}$. The $\mathrm{X}$-ray density, calculated from the formula ${ }^{2} \rho=1 \cdot 66020 \Sigma \mathrm{A} / \mathrm{V}$, is $p=5.765 \mathrm{gm} \cdot \mathrm{cm}^{-3}$.

\section{D. BrownleE}

Physical Metallurgy Section, Research Department,

Metropolitan-Vickers Electrical Co., Ltd., Manchester 17. May 23.

- Bijl and Kolkineiger, Proc. Roy. Acad. Sci. Amsterdam, 21, 405, 494,

${ }^{2}$ Bragg, W. L., J. Sci. Instr., 24, 27 (1947).

\section{Graticules as Guides in Electron-Microscope Metallography}

ONE of the greatest difficulties for the user of an electron microscope in motallography is the localization of a micrograph on the original specimen. The high magnification gives a very small area of observation which is, in general, less than $15 \mu \times 20 \mu$. It is, for example, only one three-thousandth of the area of a 1-mm. ${ }^{2}$ specimen, and it is therefore practically impossible to identify it again.

A method of solving the problem has been developed in this Laboratory. It consists in cutting a fine graticule on the polished metal surface. An ordinary diamond as used in optical microscopy is not suitable, however, because the finest lines which it can give are too coarse. This causes the replica film to break along the lines and, moreover, the lines themselves are too broad, so removing too great a part of the specimen.

We have developed an instrument, manufactured by LKB-Produkter, Ltd., at Stockholm, which enables us to scribe a metal surface with lines of width less than $2 \mu$. The instrument stands on a microscope base. A diamond, suspended from an arm, can move over the specimen surface and is lifted from it on the return stroke. The cutting pressure, which is of the order of 0.01 newton, can be adjusted. by means of a sliding weight. The limit of measurements is about $0.2 \mu$.

The replica is prepared in two stages with collodion and aluminium. To strengthen the aluminium film, we have used double evaporation, both at an angle of $10^{\circ}$ to the normal of the surface, giving an angle between the two evaporation directions of $20^{\circ}$. The collodion is dissolved in amyl acetate and the freely floating aluminium specimen is picked up on the slide.

Localization is made easior if every line in the graticule is capable of individual

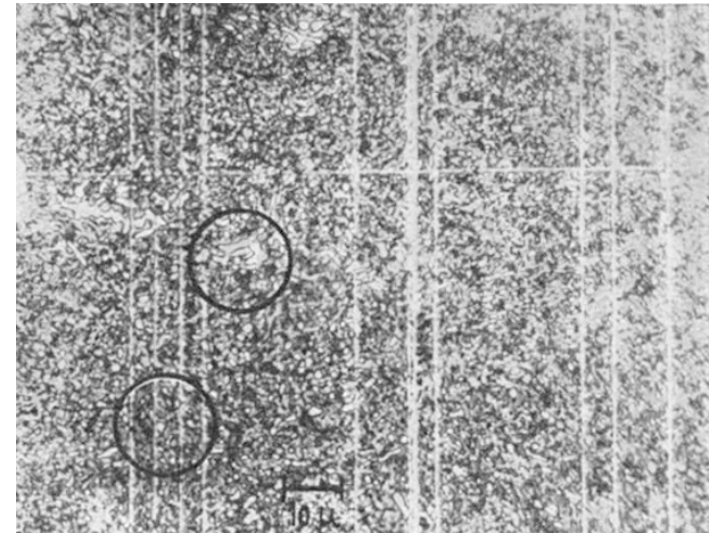

Fig. 1. Steel Sandviken $22 \mathrm{C} 1,1 \cdot 1: 1.2 \%$ C, $0.5 \% \mathrm{Cr}$;

identification. For these experiments we have chosen a master spacing of $50 \mu$, while the maximum number of lines in any one group is four. We have chosen different minor spacings in the horizontal and vertical direction, namely, $4 \mu$ and $6 \mu$ respectively.

No difficulty has been experienced due to the scribed lines being obscured by 'bars', since the geometrical regularity of the pattern renders the lines easily identified.

We have demonstrated the use of the instrument for the study of steel (Sandviken $22 C \mathbf{1}, \mathbf{1} \cdot \mathbf{1}: \mathbf{1} \cdot \mathbf{2}$ per cent carbon, 0.5 per cent chromium). The steel had been heat-treated for an hour at $780^{\circ} \mathrm{C}$.

Fig. 1 shows part of the specimen with 450 mag. nification. One of the marked parts is shown in Fig. 2 with 4,500 magnification. The light spots are carbides, whereas the background is martensite.

A comparison of the electron micrographs and optical micrographs shows good similarity in all

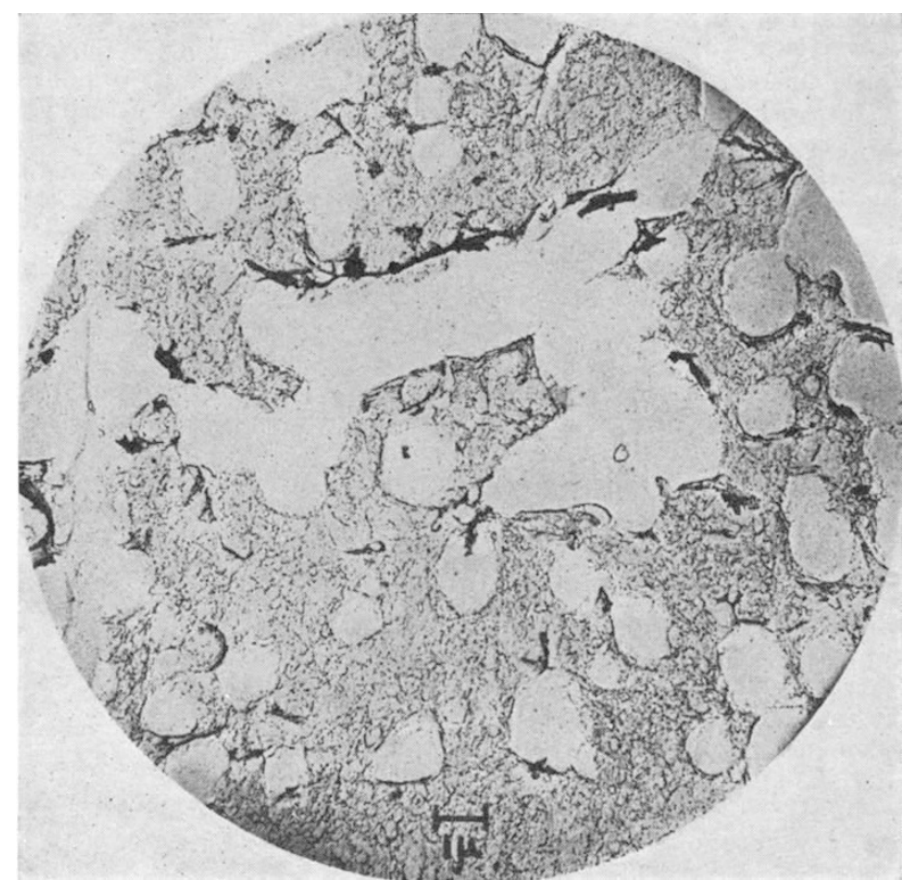

Fig. 2. Part of Fig. 1 (electron microscope, $\times 4,500$ ) 